\title{
A saga do jornalismo digital segundo o olhar de Luciana Mielniczuk
}

BACCIN, Alciane; SILVEIRA, Stefanie.C; BELOCHIO, Vivian. 25 anos de jornalismo digital no Brasil: A contribuição da pesquisadora Luciana Mielniczuk para os estudos no país. Florianópolis: Insular, 2021.

Segundo Salaverría (2015), a pesquisa destinada ao jornalismo digital tem sido desenvolvida nos últimos 25 anos. O campo nasce com o surgimento das Reportagens Assistidas por Computadores (RAC), ganha corpo na forma de webjornalismo com a popularização da Word Wide Web e se estabelece como jornalismo digital ao longo do século XXI. As discussões sobre a definição do campo giram em torno de conceitos similares, como jornalismo online, jornalismo eletrônico e jornalismo digital. Desde os primeiros estudos, fica evidente a importância que a o suporte tecnológico, a multimidialidade e o processamento de dados teriam para que essa nova investigação sobre o jornalismo tomasse contornos.

Curiosamente, mas não por acaso, a carreira da professora e pesquisadora Luciana Mielniczuk teve duração similar a este período. Foi uma vida destinada à pesquisa de um objeto em movimento, que ganhava forma no início da década de 90, quando Luciana terminava sua graduação. $\mathrm{Na}$ época, diferentes acadêmicos e núcleos de pesquisa voltavam seus olhares para um novo jeito, ainda incipiente, de se produzir e disseminar notícias. Luciana Mielniczuk foi uma dessas estudiosas que se encarregou de questionamentos seminais para que, mais tarde, uma geração de investigadores pudesse se debruçar sobre o tema.

A pesquisa sobre o jornalismo digital chega a 2021 com ramificações diversas como o Jornalismo Guiado por Dados, Jornalismo Imersivo, Jornalismo Automatizado e outros. Se pesquisar uma temática em desenvolvimento impõe suas dificuldades, certamente garante influência àqueles que trabalharam para lhe dar forma. O livro organizado por Alciane Baccin, Stefanie C. da Silveira e Vivian Belochio nos apresenta a história deste campo de pesquisa tendo a vida e obra de Luciana Mielniczuk como fio condutor. A trajetória de pesquisa da professora permite ao leitor observar os estudos sobre jornalismo digital segundo três eixos: das parcerias feitas para investigação desses objetos, a evolução das sistematizações teóricas e da formação dos pesquisadores da área.

O livro traz produções acadêmicas de Luciana, assim como de colegas e de alunos que seguem produzindo conhecimento científico sobre as manifestações digitais do jornalismo. As metodologias aplicadas em cada texto variam de acordo com o seu problema de pesquisa, mas uma revisão bibliográfica abrangente se faz presente ao longo de toda a obra. Mudanças que são constantes nesta forma de produção jornalística são abordados no livro seguindo quatro eixos

\section{Matheus Nunes}

Mestrando do Programa de Pós-Graduação em Jornalismo da Universidade Federal de Santa Catarina.

E-mail: matheuscnxavier@gmail.com 
principais: Legado e trajetória no jornalismo digital; Hipertextualidade e imersão; Colaboração e participação, por último, Bases e jornalismo guiados por dados.

Na primeira parte, o leitor se defronta com a delimitação teórica proposta por Luciana para estudos do campo. Características como interatividade, hipertextualidade, multimidialidade, convergência, memória e atualização contínua (Palacios et al., 2002), são propostas como atributos observáveis para estudiosos que procuram investigar iniciativas de jornalismo digital. As etapas de desenvolvimento da área são divididas em três gerações, assim como aspectos de cada uma dessas fases. É interessante notar que por ser uma prática jornalística em constante mutação, as características e etapas dela não são propostas como absolutas, mas como uma divisão em períodos que serve de guia para outros estudiosos.

À medida em que a produção jornalística explora os recursos oferecidos pela web, novas possibilidades surgem na forma de produzir e disseminar notícias. Animações, sons e elementos visuais passam a enriquecer a narrativa jornalística. Chats e fóruns de discussões criam ambientes de interação entre leitores e jornalistas, ao passo que fomentam a personalização dos conteúdos. Enquanto todas as informações se encontram organizadas e dispostas em hipertextos, segundo uma lógica que não segue nenhum tipo de hierarquia, apenas uma complexa trama de conexões (GOUAZÉ, 1999).

Na segunda parte do livro, o hipertexto é debatido como uma característica central do jornalismo digital e um dos mais recorrentes objetos de pesquisas acadêmicas. Entender como a web funciona envolve compreender como o hipertexto funciona ao mesmo tempo como interface de acesso e acréscimo de informações. Em sites mais complexos, o recurso hipertextual também pode ser organizado por uma base de dados, que permite ao usuário fazer consultas de maneira prática. É por meio da utilização do hipertexto seguindo a metáfora da rede que o jornalismo digital adquire sua particularidade em relação a outras formas de produção de jornalismo (BARDOEL \& DEUZE, 2000).

Uma das potencialidades do hipertexto é fomentar a colaboração e a interação no processo de construção e visualização de notícias. A terceira parte do livro se debruça sobre a colaboração que ocorre na produção de notícias na web, desde a elaboração de pautas, até a apuração participativa em bancos de dados. $\mathrm{O}$ leitor é convidado a observar como o compartilhamento de informações e a interação na web criaram um terreno fertíl para a produção de podcasts, reportagens multimídia, jornalismo cidadão e outras expressões. Ao passo que essa cultura participativa (JENKINS, 2006) permite a circulação direta de conteúdos personalizados, por outro circulação desses conteúdos hoje sequer exigem o envolvimento de jornalistas.

Se por um lado as transformações da web geram novos desafios para o exercício do jornalismo, também criam novas possibilidades. As informações disponíveis em bancos de dados de fácil acesso munem os profissionais da área de recursos para gerar um tipo de conhecimento que se aproxima científico (TRÄSEL, 2018). O Jornalismo Guiado por Dados é o tema central da quarta e última parte do livro. Como a apuração em banco de dados usa métodos das ciências sociais, modelos estatísticos e técnicas da informática para gerar notícias caracterizadas pela objetividade e busca por precisão. $\mathrm{O}$ ambiente da web alinhado às tecnologias da informação mais uma vez parece criar condições para a imersão de novas formas de fazer jornalismo.

A trajetória da pesquisa de Luciana Mielniczuk nos mostra o caráter cambiante do universo on-line, assim como do jornalismo feito na web. Deixando mais de 50 orientações e 37 trabalhos publicados, a repercussão de suas ideias se faz perceptível não só nos textos que publicou, mas nas mentes que ajudou a moldar. O livro em questão será útil para estudantes de graduação que buscam um primeiro contato com os estudos sobre jornalismo digital, alunos de pós-douto- 
rado e professores que precisam preparar aulas, ou fundamentações teóricas para trabalhos acadêmicos. Essa homenagem à vida e obra de Luciana é capaz de garantir uma experiência tanto teórica, quanto bibliográfica, que instrui na medida em que inspira novos pesquisadores.

\section{Referências}

BARDOEL, J.; DEUZE, M. Network journalism: converging competences of old and new media professionals. Australian Journalism Review 23 (2), p. 91-103. Disponível em: https://www.researchgate.net/publication/267969191_Network_Journalism_Converging_competences_of_old_and_new_media_professionals. Acesso em: 5 nov. 2000.

GOUAZÉ, Jean. Os Dispositivos da Comunicação. Palestra proferida na FACOM/ UFBA, Salvador, Brasil, em 25/10/1999.

JENKINS, H. Convergence culture: where old and new media collide. New York: New York University, 2006.

PALACIOS, M.; MIELNICZUK, L. Considerações para um estudo sobre o formato da notícia na web: o link como elemento paratextual. Pauta Geral, Salvador, v. 4, p. 33-50, 2002.

SALAVERRÍA, R. Digital journalism: 25 years of research. Review article. El profesional de la información (EPI), v. 28, n. 1, 2019.

TRÄSEL, M. R. Entrevistando planilhas: estudo das crenças e do ethos de um grupo de profissionais de jornalismo guiado por dados no Brasil. 2014. Tese (Doutorado em Comunicação Social) - Programa de Pós-Graduação em Comunicação Social, Faculdade de Comunicação, Pontifícia Universidade Católica do Rio Grande do Sul, Porto Alegre, 2014. Disponível em: <http://tede2.pucrs.br/tede2/ bitstream/tede/4590/1/461784.pdf>. Acesso em: 5 abr. 2018. 